\title{
A Study on Congenital Anomalies in Fetuses based on Educational and Socio-Economic Status of the Mother
}

\author{
Authors \\ Dr D.Sudhakar Babu ${ }^{1}$, Dr V.Sailaja ${ }^{2}$, Dr M.Padmavathi ${ }^{3}$ \\ Government Medical College Nizamabad, Telangana \\ Email: dasarisudhakar2@gmail.com \\ Army College of Dental Sciences, Secunderabad, Telangana \\ Email: sailajamed@gmail.com \\ Government Medical College, Adilabad, Telangana \\ Email: poreddy.mallela@gmail.com
}

\begin{abstract}
Aims and Objectives: To assess the association of the various congenital malformations based on maternal education and socio-economic status.

Materials and Methods: Fetuses of pregnant women attending government hospitals in Hyderabad during the a period of one year from October 2011 to September 2012 were screened through ultrasonographic evaluation in the second trimester (12wks to 28wks) for congenital anomalies considering the maternal educational status and socio-economic status according to Kuppuswamy's classification.

Results: The congenital anomalies are seen more affecting uneducated women of low socio-economic status in our study

Conclusion: congenital anomalies are more commonly seen in illiterate women \& to prevent them more focus should be laid on maternal education, pre-marital councelling,antenatal care, supplementation with folic acid, prenatal ultrasonography \& genetic studies in at-risk individuals.

Keywords: congenital defects, fetal anomalies, maternal education, socio-economic status, prenatal ultrasonography
\end{abstract}

\section{Introduction}

Congenital anomalies are defined as conditions that result in a malformation, deformation or disruption in one or more parts of the body which are present at birth and can have a serious adverse affect on health, development or functional ability of the individual.

With the development of science and with advanced screening techniques, in modern era the task of identifying the causative factors, and early detection of congenital malformations has become easier. Congenital malformations not only affects the diseased but also extends to many at risk individuals as well as to their families and adds to the socio-economic burden of the society.

\section{Materials and Methods}

The present study was done on congenital malformations occurring in foetuses of pregnant women who attended two Government Maternity Hospitals in Hyderabad for antenatal checkup, during a period of one year from October 2011 to 
September 2012 Foetuses of all pregnant women of different socio-economic status \& education levels were screened through ultrasonographic evaluation in the second trimester (12 wks to 28 wks) for congenital anomalies

The details regarding the maternal education, antenatal history and other risk factors were taken $\&$ recorded as per proforma.

Informed consent was obtained from the parents and the data collection was carried out in the vernacular language of the parents.

\section{Results}

In our study, a total of 112 cases of congenital malformations were observed. These were further categorised according to maternal education \& socio-economic status at different maternal age groups and the findings were tabulated

The socioeconomic status of parents of congenitally malformed fetuses were classified according to Kuppuswamy's classification, based on Education, Occupation and Family Income per month.

Table 1 Distribution of cases based on Socio Economic Status According To Kuppuswamy's Classification (Kuppuswamy et al, 2007) ${ }^{1}$

\begin{tabular}{|l|c|c|}
\hline Social class & No of cases & \% \\
\hline Upper class & 0 & 0 \\
\hline Upper middle class & 33 & 29.46 \\
\hline Lower middle class & 46 & 41.07 \\
\hline Upper lower class & 17 & 15.17 \\
\hline Lower class & 16 & 14.28 \\
\hline Total & 112 & 100 \\
\hline
\end{tabular}

In our study, 33 cases (29.46\%) belonged to upper middle class whereas 46 cases $(41.07 \%)$ were in lower middle class. But no cases were observed in upper class. (Table-1)

Most of the patients attending the Government hospitals belong to low socioeconomic group and their literacy rate was low.

Table 2 Distribution of cases based on Education Status of Parents

\begin{tabular}{|l|c|c|c|c|}
\hline \multirow{2}{*}{ Education status } & \multicolumn{2}{|c|}{ Father } & \multicolumn{2}{c|}{ Mother } \\
\cline { 2 - 5 } & No & $\%$ & No & $\%$ \\
\hline Illiterate & 18 & 16.07 & 46 & 41.07 \\
\hline Primary school & 28 & 25 & 35 & 31.25 \\
\hline High school & 35 & 31.25 & 23 & 20.53 \\
\hline Intermediate & 18 & 16.07 & 8 & 7.14 \\
\hline Degree & 13 & 11.60 & 0 & 0 \\
\hline
\end{tabular}

Among the 112 cases, $16.07 \%$ (18/112) of the fathers and $41.07 \%$ (46/112) of mothers did not attend school at all (Illiterates). 25\% (28/112) of fathers and $31.25 \%(35 / 112)$ of mothers were able to get primary school education (I to VII std.). $31.25 \%$ (35/112) of fathers and $20.53 \%$ (23/112) of mothers reached upto secondary school level. Only $7.14 \%$ (8/112) of mothers and $16.07 \%$ (18/112) of fathers attended pre-university level, where as no mothers in our study attended the degree or diploma courses and only $11.6 \%$ (13/ 112) of fathers had degree or diploma (table 2 ).

\section{Discussion}

Increased awareness of various anomalies in the general population, improvement in diagnostic modalities, advancement of knowledge in pathophysiological aspects of the defects and identification of the teratogenic agents involved in causing various birth defects helped to some extent to identify the causative factor for few congenital malformations.

Parent's education is an important factor in determining the frequency of congenital anomalies. Educated parents especially an educated mother will be aware of the role of maternal nutrition, various teratogenic agents, gap between successive pregnancies, family planning, regular antenatal checkups, risks of consanguineous marriages and their role in malformations.

Psychomotor retardation, primary amenorrhoea and mental retardation topped the list of disorders encountered in children born to consanguineous parents (Mokhtari \& Bagga) ${ }^{2}$

Prematurity,increased maternal age, increasing birth order and low birth weight were found to have a higher risk of congenital anomalies (Neelu Desai et al, ${ }^{3}$; Amar Taksande et al ${ }^{4}$ ).

Worldwide surveys have shown that the birth prevalence of congenital anomalies varies greatly from country to country (Anupam Kaur and Jai Rup Singh, ${ }^{5}$ ). These variations may be explained by social, racial, ecological, and economical influences. 
Parent's awareness about consanguineous marriages and its risk in causing malformations is a preventive factor in congenital malformations and other hazards. (Mehrabi kushki et al, ${ }^{6}$ )

Maternal education regarding regular periodic antenatal check-ups with early gestational ultrasound scanning has a significance role in identification of various congenital anomalies

Long et $a l^{7}$ done a comparative study of routine versus selective fetal anomaly ultrasound scanning and found routine scanning to be economically justifiable.

Munim et $a l^{8}$ in their study successfully diagnosed fetal abnormalities in $48.8 \%$ of cases by antenatal ultrasonography. Some anomalies like anencephaly can be picked as early as 12 wks when skull ossification is complete (Nafees et al ${ }^{9}$ ).

Table 3 Maternal Education In Various Study Groups

\begin{tabular}{|c|c|c|c|c|c|c|}
\hline S1 & Study & tot & \multicolumn{4}{|c|}{ Education } \\
\cline { 4 - 7 } & & (n) & $\begin{array}{c}\text { Illiter } \\
\text { ate }\end{array}$ & $\begin{array}{c}\text { High } \\
\text { school }\end{array}$ & $\begin{array}{c}\text { Inter- } \\
\text { mediate }\end{array}$ & $\begin{array}{c}\text { Degre } \\
\mathrm{e}\end{array}$ \\
\hline $\mathbf{1}$ & $\begin{array}{c}\text { Zilfalil et } \\
\text { al,1997 }\end{array}$ & 44 & 9.1 & 60.1 & 8.1 & 22.7 \\
\hline $\mathbf{2}$ & $\begin{array}{c}\text { Present } \\
\text { study,2012 }\end{array}$ & 112 & 41.07 & 51.78 & 7.14 & 0 \\
\hline
\end{tabular}

Zilfalil et $\mathrm{al}^{10}$ in their extensive study observed increased rate of malformations, in mothers with College / University degree education, when compared to control group. (Table 3)

In our study, among 112 cases of congenital malformations, the parental education level was low overall. $41.07 \%$ of mothers were illiterate \& none have attended degree/ diploma college.

Maternal education level was very low when compared to paternal education.

\section{Conclusions}

The present study gave us an idea regarding the frequency of distribution of congenital anomalies and also its relation with maternal education \& socio-economic status .Most of the aetiological factors remain obscure, but require detailed history taking and thorough investigations for the early diagnosis and treatment.
Maximum of $41.07 \%$ of cases were from lower middle socioeconomic class (class III according to Kuppuswamy's socioeconomic class grading), $29.46 \%$ were from upper middle socioeconomic class (class II) $15.17 \%$ were from upper lower socioeconomic class (class IV) and none were from upper socioeconomic class.

$>16.07 \%$ of fathers and $41.07 \%$ of mothers of the cases were illiterates, $11.6 \%$ of fathers studied upto degree/diploma and none of the mothers attended degree/ diploma college.

More stress should be laid on prevention by regular antenatal care and avoidance of known teratogenic agents, maternal education, Premarital counselling, Prenatal ultrasonography at about 812 weeks, supplementation of folic acid prior to conception to every pregnant women especially in the embryonic period.

Education related to Genetic studies should be made mandatory for all the pregnancies presenting with family history of suspected chromosomal anomalies and in pregnancies of repeated abortions/still births which are highly suggestive of chromosomal aberrations and in such cases prenatal genetic counselling is a must.

\section{References}

1. Kumar et al (2007). Kuppuswamy's socioeconomic status scale-Updating for 2007. Indian J Pediatr; 74:1131-2.

2. Roya Mokhtari, Amrita Bagga (2003), 'Consanguinity, genetic disorders and malformations in the Iranian population'. Acta Biologica Szegediensis Volume 47(14):47-50.

3. Neelu A Desai, Avinash Desai (2006), Congenital Anomalies: A Prospective Study. Bombay Hospital Journal. July; 442-445.

4. Amar Taksande, et.al (2010), Congenital malformations at birth in Central India: A rural medical college hospital based data. 
Indian J Hum Genet. Sep-Dec; 16(3): 159163.

5. Anupam Kaur and Jai Rup Singh (2010), Chromosomal Abnormalities: Genetic Disease Burden in India. Int J Hum Genet, 10(1-3): 1-14 .

6. Mehrabi Kushki Msc, B. Zeyghami $\mathrm{PhD}$ (2005), The effect of Consanguineous Marriages on Congenital Malformation. Journal of Research in Medical Sciences; 10(5): 298-301

7. G Long, A Sprigg (1998),A comparative study of routine versus selective fetal anomaly ultrasound scanning. J Med Screen; 5:6-10.

8. Shama Munim, Salva Nadeem, Nadya Ali Khuwaja (2006), The Accuracy of Ultrasound in the Diagnosis of Congenital Abnormalities. J Pak Med Assoc. January; Vol. 56, No. 1: 16-18.

9. Muhammad Nafees et.al (2006), Congenital Fetal Anomalies Antenatal Ultrasound Detection. www.paf mj.org/printdetail.php?id $=100 \& \mathrm{t}=0$.

September; Issue 3:1-6

10. Zilfalil BA. and Rowani MR (1997), Online Birth Defects in Newborn at Hospital Universiti sains Malaysia, Kelantan. Www.eimjm.com/Vol2No1/Vol2-No1-B3.htm 